\title{
The effect of selection on genetic variation in chicken small population
}

\author{
J. TARKOWSKI \\ Agricultural Academy, 20-934 Lublin, ul.Akademicka 13, Poland
}

Changes in genetic variation of sexual maturity, initial and 500-days egg production during 12 year of selection for these traits were estimated by investigating the changes of their $h^{2}$ coefficients. Three variants of calculations of $h_{2}$ were used utilizing the production records for period of 2,3 or 4 consecutive generations respectively. The results indicate, that generally the levels of $h^{2}$ of studied traits decreased at the beginning of selection and then increased except the initial egg production whose $h^{2}$ tended to fall again at the end of selection period. The $h^{2}$ values estimated for total period of selection were $0.38 \pm 0.06 ; 0.37 \pm 0.07$ and $0.35 \pm 0.06$ for these traits respectively.

\section{Correlations between the thyroid activity $\left(T_{3}\right.$ in vitro test) in young female cattle and their future milk yield}

\author{
G. SEELAND, P. REINECKE, G. LEUTHOLD, G. SCHONMUTH \\ Sektion Tierproduktion und Veterinärmedizin der Humboldt-Universität zu Berlin, \\ Bereich Tierzüchtung und Haustiergenetik, D.D.R. 1040 Berlin, Invalidenstr. 42
}

The $\mathrm{T}_{3}$ in vitro test was applied to determine the free combining capacity of thyroxin-binding globulin ( $T_{3}$ value) in female cattle aged between 3 and 5 months. That capacity is indirectly correlated with the thyroid hormons level in the blood. Heritability coefficients for the $T_{3}$ value ranged between 0.248 and 0.644 . Medium negative genetic correlations $\left(r_{g}=-0.285\right.$ to -0.344$)$ were found between $T_{3}$ value and milk quantity, while medium positive genetic correlations $\left(r_{g}=0.349\right.$ to 0.444$)$ existed between the $T_{3}$ value and butterfat and milk protein contents. The coefficients of genetic correlation between $T_{3}$ value and butterfat quantity were about zero 0.017 to -0.024$)$ and those between $T_{3}$ value and milk protein quantity were slightly negative $(-0.118$ to -0.192 ). Phenotypic correlation coefficients generally were much lower, their signs, however, being the same as for the genetic correlation coefficients.

\section{Genetic parameters of ovarian cyst incidence in Swedish dairy cattle}

\author{
L. JANSON and I. INGVARSSON \\ Department of Animal Breeding and Genetics, \\ Swedish University of Agricultural Sciences, S-750 07 Uppsala, Sweden
}

Swedish AI data from two AI organisations, SKARA and MALMEN were analysed in order to estimate effects of non-genetic factors and to estimate genetic parameters for cystic ovaries in dairy cattle. The frequency of cystic ovaries was very low for heifers, below $0.4 \mathrm{p}$. 100 . Among cows the frequency increased gradually with lactation number up to the fourth lactation. The incidence of ovarian cysts was lowest for cows calving in March, April, May and highest in September, October and November. The heritability for cystic ovaries fell within the range 0.004 to 0.041 depending on the measure used. The frequency of cystic daughters for 39 Swedich Red and White bulls with more than 500 daughters each varied between 0.5 p. 100 and 12.4 p. 100 . 